\title{
Predicting Education Science Students' Statistics Anxiety: The Role of Prior Experiences Within a Framework of Domain-Specific Motivation Constructs
}

\author{
Günter Faber*, a and Heike Drexler ${ }^{a}$ \\ aLeibniz University of Hannover (LUH) Institute of Psychology, Hannover, Germany
}

Submitted: January 10, 2019 | Peer reviewed: April 11, 2019 | Accepted: May 7, 2019 | Published: May 25, 2019

\begin{abstract}
Based on a cognitive-motivational modeling of construct relations, this study analyzed the role of prior statistics experiences within a framework of domain-specific self-concept and value variables to predict education science students' statistics anxiety. Data were analyzed from two independent samples comprising 113 and 87 participants-using the passing of a statistics exam as the experience measure in each case. In both samples, the results of three-way analyses of variance demonstrated students' statistics anxiety to be substantially explained by their negative utility value and self-concept but only to a minor extent by their prior statistics experiences. Students' statistics anxiety appeared to be dependent on value and self-concept scores across all experience levels. Though producing somewhat varying effect patterns, the findings from both samples led to similar effects, indicating the crucial role of self-belief variables. Results are discussed in terms of conceptual, methodological, and instructional implications.
\end{abstract} concept

Keywords: statistics anxiety; prior statistics experiences; utility value; mathematics self-

\section{Introduction}

In higher education settings, the learning of research methods, most notably the acquisition of statistical knowledge and competencies, can be stressful or anxiety provoking. Many undergraduate and graduate students from social science, education, psychology, and business programs struggle with statistics (Mji \& Onwuegbuzie, 2004; Onwuegbuzie \& Wilson, 2003). When dealing with the requirements of quantitative methods courses that are commonly compulsory for earning the degree, these students mostly suffer from strong failure expectations and frequently experience feelings of apprehension and personal threat. They perceive methodological competencies difficult to acquire and less useful for current studies and later professional development (Markle, 2017; Murtonen \& Lehtinen, 2003; Murtonen, Olkinuora, Tynjälä, \& Lehtinen, 2008; Zeidner, 1991). As a result, they are at risk for developing and maintaining a heightened level of anxiety in the face of statistical demands-in particular, when being confronted with statistical tasks of data gathering, processing, and interpreting (Cruise, Cash, \& Bolton, 1985). Empirical analyses from diverse conceptual, methodological, and institutional backgrounds have yielded insights into the development, structure, and consequences of higher education students' statistics anxiety. These studies have established a broad-based research with the goal of clarifying and elaborating the construct (Onwuegbuzie \& Wilson, 2003; Ralston, Maclnnes, Crow, \& Gayle, 2016).

\footnotetext{
*Author correspondence: faber@psychologie.uni-hannover.de
}

Suggested Citation: $F \equiv$ G., \& Drexler, H. (2019). Predicting education science students' statistics anxiety: The role of prior experiences $\bar{\tau}$ in a framework of domain-specific motivation constructs. Higher Learning Research Communications, 9(1) (Online Version). http://dx.doi.org/10.18870/hlrc.v9i1.435 


\section{Conceptual Perspectives on Statistics Anxiety}

Structurally, emerging statistics anxiety has to be considered a multidimensional construct (Hodapp \& Benson, 1997) that reflects the complex interplay of cognitive, motivational, and physiological components (Rost \& Schermer, 1989; Zeidner, 1998). Based on empirical findings of test anxiety research, statistics anxiety can be defined as a domain-specific form of evaluation anxiety that manifests as worry cognitions that repeatedly occur, interfering thoughts during task completion, marked states of emotional tension, and physiological arousal (Zeidner, 1991). In particular, cognitive worries and task-irrelevant thoughts had been demonstrated to stress students' executive resources, impede their learning approach, and eventually impair their academic performance (von der Embse, Jester, Roy, \& Post, 2018). This debilitating effect of worry cognitions appears to be mainly caused by their strongly biased and task-irrelevant mode of information processing (Sarason, 1984; Schwarzer, 1996). Accordingly, students experiencing a heightened level of statistics anxiety are persistently afraid they won't master a statistically loaded task or a statistical course exam (Cruise et al., 1985). They also tend to use less adaptive learning and test-taking strategies (Spada \& Moneta, 2012; Virtanen, Nevgi, \& Niemi, 2013; Warr \& Downing, 2000). However, for the most part, previous research on statistics anxiety among university students has disregarded the cognitive components of the construct (Faber, Drexler, Stappert, \& Eichhorn, 2018). Rather, relevant studies focus on its emotional and physiological components (Cruise et al., 1985; Onwuegbuzie \& Wilson, 2003; Papousek et al., 2012).

\section{Empirical Research Findings on Statistics Anxiety}

Notwithstanding, numerous studies in the field have increasingly clarified the nature of statistics anxiety-in particular, with regard to its developmental antecedents, contextual references, individual determinants, and educational consequences (Cruise et al., 1985; Onwuegbuzie \& Wilson, 2003; Zeidner, 1991). Several studies consistently separated university students' statistics anxiety from their general test and mathematics anxiety. Thus, relevant measures of statistics anxiety should claim construct validity to a required extent (Baloğlu, 2002; Paechter, Macher, Martskvishvili, Wimmer, \& Papousek, 2017; Sesé, Jiménez, Montaño, \& Palmer, 2015). Furthermore, research in the field has identified a wide variety of risk factors that can predict statistics anxiety. Across diverse designs, methodological features, and student samples, certain cognitive and motivational characteristics have consistently explained the formation of statistics anxiety-in particular, students' inadequate mathematical knowledge, lowered competence beliefs, and negative attitudes toward the value of statistical competencies (Emmioğlu \& Capa-Aydin, 2012; Onwuegbuzie \& Wilson, 2003).

However, as relevant multivariate analyses have repeatedly demonstrated, these antecedents and determinants operate in a complex manner. They constitute a relational pattern of direct and indirect effects, each of them specifically contributing to the development and maintenance of statistics anxiety (Chiesi \& Primi, 2010; González, Rodrígez, Faílde, \& Carrera, 2016; Macher et al., 2013; Nasser, 2004; Onwuegbuzie, 2003; Sesé et al., 2015; Tremblay, Gardner, \& Heipel, 2000). Similarly, the level of individually experienced statistics anxiety has been shown to adversely affect students' learning approach and performance in the domain (González et al., 2016; Kesici, Baloğlu, \& Deniz, 2011; Macher, Paechter, Papousek, \& Ruggeri, 2012; Onwuegbuzie, 2003; Sesé et al., 2015).

Overall, research in the field indicates the students most at risk of failing a university statistics course are those who have poorer math grades at school, display inappropriate mathematical competencies, perceive their mathematical or statistical competencies as low, and value statistics as a less useful subject of study. These students experience a heightened level 
of statistics anxiety (Finney \& Schraw, 2003; Galli, Ciancaleoni, Chiesi, \& Primi, 2008; González et al., 2016; Onwuegbuzie, 2000).

\section{The Role of Prior Statistics Experiences}

Various studies considered prior statistics experience as a relevant background variable. Seemingly, these analyses were geared toward the examination of a positive impact that familiarity with statistical procedures and course requirements should have on students' domainspecific motivation, attitudes, or performance (Carmona, Martínez, \& Sánchez, 2005; Dempster \& McCorry, 2009). Following the analysis of Sutarso (1992), who demonstrated significantly lower anxiety scores in the subgroup of students with more statistics courses taken before the exam, Onwuegbuzie (2003) had also substantiated a small but significant relation between prior statistics experience and self-concept. However, he did not explicitly assess the statistics anxiety variable. Instead, he had used the Computational Self-Concept subscale from the Statistical Anxiety Rating Scale instrument (Cruise et al., 1985). Although there is theoretical and empirical overlap between the self-concept and anxiety variable, they represent distinct constructs and should not be treated as interchangeable.

In another study, students' subjective rating of prior experiences did not significantly predict grades on a statistics exam (Slootmaeckers, 2012). These findings suggest that prior statistics experiences explain self-beliefs more than actual achievement in statistics. Dempster and McCorry's (2009) study supported this conclusion. Being more frequently involved with learning statistics is likely to increase confidence in typical requirements and methods (Waples, 2016) and thereby reduce apprehension and fear of failure.

As demonstrated elsewhere (Schönwetter, Clifton, \& Perry, 2002), familiarity with course materials might also enhance students' perceived control. In contrast, other relevant studies (Birenbaum \& Eylath, 1994; Chew \& Dillon, 2012, 2014a; Schutz, Drogosz, White, \& DiStefano, 1998; Townsend, Moore, Tuck, \& Wilton, 1998) did not substantiate any significant impact of prior statistics experiences on students' statistics anxiety. Likewise, students with and without prior experiences appeared to not significantly differ in their valuing of statistical competencies (Hannigan, Hegarty, \& McGrath, 2014; Slootmaeckers, 2012).

In sum, across various measures of prior statistics experiences, most findings do not support the assumption of positive effects. However, relevant studies suffered from conceptual and methodological limitations - the assumption of a negative relation between prior statistics learning and statistics anxiety must be considered a simplified view. That is because the impact of previously taken statistics courses should depend on students' outcome experiences (Cano, Martin, Ginns, \& Berbén, 2018). Students with favorable course experiences will develop more positive competence beliefs and attitudes as well as a lowered level of statistics anxiety (Galli et al., 2008; González et al., 2016). Without controlling for the direction and magnitude of individually existing self-beliefs and attitudes, empirical analyses of prior experiences disregard the potential appearance of both positive and negative relations with students' statistics anxiety in the same sample. These studies, thus, are at risk because they omit potential moderator effects. Consequently, the relation between prior statistics experiences and statistics anxiety should be more adequately analyzed within students' cognitive-motivational system of academic self-beliefs (Stiensmeier-Pelster \& Otterpohl, 2018). Specifically, empirical findings that substantiate the role of domain-specific competence beliefs and task values in predicting students' statistics anxiety and attitudes lend support to this extension of research efforts (Chiesi \& Primi, 2010; González et al., 2016; Hood, Creed, \& Neumann, 2012; Onwuegbuzie, 2003; Sesé et al., 2015). 


\section{Theoretical Framework and Research Hypotheses}

The present study is conceptually rooted in a social-cognitive understanding of motivation processes, namely, in both the expectation-value theory of academic motivation (Wigfield \& Eccles, 2000) and the control-value theory of academic emotions (Pekrun, 1988; Pekrun, Frenzel, Goetz, \& Perry, 2007). The purpose of the study is to understand the effect of prior statistics experiences on students' statistics anxiety in the context of their domain-specific competence expectations and task values.

Following this conceptual perspective, the formation of statistics anxiety should be substantially affected by students' competence expectations or self-concept. As test anxiety research demonstrates, lowered academic self-concepts strongly predict test anxiety responses (Ahmed, Minnaert, Kuyper, \& van der Werf, 2012; Faber, 2012; Goetz, Pekrun, Hall, \& Haag, 2006). In most cases, high-anxious students reported a lowered self-concept of mathematics or statistical competencies (Bandalos, Yates, \& Thorndike-Christ, 1995; Benson, 1989; González et al., 2016; Macher et al., 2012; A. Williams, 2014; Zeidner, 1991). Thus, students with lower competence beliefs will predominantly expect to fail statistical tasks and develop a higher level of apprehension and worry.

Furthermore, according to the assumption of the expectancy-value approach (Wigfield, Hoa, \& Klauda, 2009), students' perceived value of statistical competencies should have a direct impact on their statistics anxiety, as well. Following relevant research findings, strong perceptions of statistics as less useful should predict a heightened level of statistics anxiety (Baloğlu, 2002; Chew \& Dillon, 2014b; Chiesi \& Primi, 2010; Papousek et al., 2012). Although domain-specific self-concept and utility value variables had been evidenced to correlate to some extent (Chew \& Dillon, 2014b; Dempster \& McCorry, 2009; Hood et al., 2012; Papousek et al., 2012), they should still uniquely contribute to the variance of the anxiety variable.

Within this framework, the role of students' prior statistics experiences needs to be considered in a more differentiated manner. In particular, the impact of prior statistics experiences will vary in some respects. Prior experiences can refer to students' successes or failures in statistics and, thus, be positive or negative in nature. In each case, the cognitive-motivational processing of anxiety formation will operate differently in the following ways.

(a) Students with prior statistics failure experiences will likely develop a negative self-concept, finding learning statistics challenging and believing they are prone to failure. Thus, they will value statistical knowledge and competencies as less useful and display a heightened level of statistics anxiety.

(b) Students with prior success experience will likely develop a positive self-concept and weak negative value beliefs and, therefore, perceive their previous statistical learning more positive. Hence, they will display a lower level of statistics anxiety. For students without prior statistics experience, the same effect of the self-concept and the value variable should be expected; however, their statistics anxiety will be more strongly affected by domain-specific beliefs, in particular, self-concept and utility value.

(c) Students without prior experience who perceive their competencies as low will mostly expect to fail in learning statistics, tend to negatively value the usefulness of statistical competencies, and will thus likely develop a heightened level of statistics anxiety.

(d) Students without prior experience who perceive their competencies as sufficient or high will most likely anticipate success in learning statistics and expect to master statistical course requirements. Therefore, they are less likely to devalue statistical competencies and will display a lower level of statistics anxiety.

Consequently, in each case, students with a lowered self-concept will report a negative utility value and statistics anxiety more than students with a heightened self-concept, whether they have gained positive or negative statistics experiences or not (Chamberlain, Hillier, \& Signoretta, 2014; Galli et al., 2008). 
Thus, the present study focuses on the role students' prior passing of a statistics exam will play in the formation of their statistics anxiety. In terms of a factorial research design (Field, 2013), mean differences in the anxiety variable are assumed to be explained by significant effects of the self-concept and utility value variables. However, the potential effect of prior success experiences-namely, the passing of an exam-on students' anxiety level appears less clear. The analysis of anxiety differences between students having or not having passed a statistics exam should at least consider three distinct effect patterns: Prior success experiences will (a) directly reduce students' anxiety level beyond the impact of their self-concept and utility value, (b) indirectly reduce students' anxiety level by significant interaction effects with the self-concept and utility value variables, or (c) not substantially contribute to reducing students' anxiety level. In that regard, the present study primarily addressed the impact of students' motivational characteristics to clarify the role of prior experiences-instead of (once again) merely examining their explanative value.

According to these conceptual considerations, the present study aimed to analyze the following research hypotheses:

Hypothesis 1: Across both levels of statistics experiences, students with a high mathematics self-concept will report a lower level of statistics anxiety (main effect hypothesis).

Hypothesis 2: Across both levels of statistics experiences, students with a low negative utility value of statistical competencies will report a lower level of statistics anxiety (main effect hypothesis).

Hypothesis 3: Within the subgroup displaying a high mathematics self-concept (and a low negative utility value), students with prior success experiences will report a lower level of statistics anxiety than their counterparts without prior success experiences (interaction effect hypothesis).

Hypothesis 4: Within the subgroup displaying a low mathematics self-concept (and a high negative utility value), students with prior success experiences will report a lower level of statistics anxiety than their counterparts without prior success experiences (interaction effect hypothesis).

\section{Method}

\section{Sample and Procedure}

Data from two independent samples were analyzed. In both samples, students were provided with sufficient information to make an informed decision as to whether to take part in the study. Their participation was on a voluntary basis only. To meet the institution's ethical requirements, we sought informed consent from the participants prior to data collection. Each participant's name was substituted with a pseudonym to keep the database anonymous.

Sample 1 consisted of 113 graduate students ( $n=94$ female, $n=19$ male) from master'slevel courses in educational sciences $(n=80)$ and special education $(n=33)$. They were all enrolled in a compulsory course on empirical research methods. The participation rate was sufficiently high at $82 \%$. Seventy-five of the students had already acquired elementary statistical knowledge during their undergraduate program, whereas 38 were required to attend a course in basic descriptive and inferential statistics. Neither the subgroup with nor without statistical knowledge significantly differed with respect to gender, $\chi^{2}(1)=.043, p>.05$, or age, $t(111)=-$ $0.634, p>.05$.

Sample 2 was thought to validate the findings from Sample 1 a year later. It consisted of 87 graduate students from the same master's-level courses: educational sciences $(n=59)$ and special education $(n=28)$. The sample was predominantly female $(n=74)$. Again, students were enrolled in a compulsory course on empirical research methods. The participation rate was high at $89 \%$. Fifty of the students had acquired statistical knowledge during their undergraduate 
program, whereas 37 had yet to attend an introductory statistics course. There were no subgroup differences in gender, $\chi^{2}(1)=.067, p>.05$, or in age, $t(82)=0.790, p<.05$.

In both samples, all relevant data were gathered during the course's first term. A questionnaire including all items to assess students' domain-specific experiences and self-beliefs was administered. To prevent a priming effect of the self-concept items, they were presented at the end of the questionnaire (Podsakoff, MacKenzie, Lee, \& Podsakoff, 2003).

\section{Measures}

Prior statistics experiences. Because relevant studies had assessed students' prior statistics experiences in various ways-namely, by means of subjective ratings (Dempster \& McCorry, 2009; Slootmaeckers, 2012) and the number of previously taken statistics courses (Birenbaum \& Eylath, 1994; Chew \& Dillon, 2012; Hannigan et al., 2014; Onwuegbuzie, 2003; Sutarso, 1992) -in the present study, an objective (formal) measure was used. In both samples, students' prior experiences with statistics referred to the successful passing of a statistics exam in their undergraduate program; passing was coded as 0 (no) or 1 (yes).

Self-concept in mathematics. Because the study samples consisted of both students with and without statistical experiences (see Table 1), their measures of domain-specific competence beliefs did not refer to their statistics but to their mathematics self-concept (González et al., 2016; Onwuegbuzie \& Wilson, 2003). This was assessed using a nine-item scale addressing most recent learning experiences at school and competence beliefs with regard to meeting subject-specific demands. Most items originated from well-proven instruments, namely, the research scale for assessing learners' spelling-specific self-concept (Faber, 2012), the research scale for assessing students' subject-specific self-concepts (Möller, Streblow, Pohlmann, \& Köller, 2006), and the self-concept grid for assessing students' subject-specific selfconcepts (Rost, Sparfeldt, \& Schilling, 2007). They were selected due to their content validity to unambiguously represent students' subject-specific competence beliefs and their psychometric properties, especially their factor loadings and item-total correlations. All items were adapted and phrased retrospectively (e.g., "I tried hard in mathematics, but I did not perform very well"). Items were summed up to create the score, with high scores indicating positive competence beliefs. In both study samples, the scale's internal consistency coefficient was very high (Cronbach's $\alpha=$ .93 and .94 in Samples 1 and 2, respectively).

Utility value. Utility value was measured using a five-item scale in Sample 1 that addressed the perceived utility of statistics for students' current studies and intended career. To reduce acquiescence or social desirability bias in students' responses, scale items were both positively and negatively worded (e.g., "Adequate knowledge in statistics will help me to attain better course grades"; "Statistics will not play an important role in my future professional life"). The scale's reliability was acceptable (Cronbach's $\alpha=.72$ ). In Sample 2, to improve the instrument's content validity and reliability, an extended version with eight items was used (Faber et al., 2018). Reliability was acceptable (Cronbach's $\alpha=.75)$. In both samples, principal component analyses revealed the negatively worded items to load the strongest on the latent factor $(a>.50)$ and, therefore, to determine the factor's meaning (Pituch \& Stevens, 2016). High sum scores indicated students perceived statistics as being less useful for their current studies and later professional development.

Statistics anxiety. A 17-item scale was developed to measure a student's worry, avoidance, and emotionality cognitions concerning statistical demands (Faber et al., 2018). Each item was rated on a 4-point scale referring to a representative range of statistically relevant task features, course situations, and examination procedures that students would typically encounter in their undergraduate or graduate program (e.g., "It would be difficult for me to discuss statistical content adequately in my papers"). In both samples, a principal component analysis revealed a unidimensional pattern of factor loadings and, thus, led to the formation of the final scale version 
including all items. A total score was computed by summing all items. High scores indicated a heightened level of students' anxiety experiences. In both samples, the scale's internal consistency coefficient was very high (Cronbach's $\alpha=.92$ and .94 in Samples 1 and 2, respectively).

\section{Data Analysis}

To test research hypotheses, a 2 (Prior Statistics Experiences) $\times 2$ (Mathematics SelfConcept) $\times 2$ (Negative Utility Value) analysis of variance was conducted for each sample. In both samples, the self-concept and utility value variables were recoded using median split, thus creating a dichotomous variable reflecting high and low manifestations of each. The experience variable was already in a dichotomous format.

To test research Hypotheses 1 and 2, the effects of mathematics self-concept and negative utility value were analyzed. Hypotheses 3 and 4 were tested by examining the results of interaction effects of the mathematics self-concept and negative utility value variables with the prior statistics experiences variable. In view of sample size and lack of variance homogeneity, the robust Brown-Forsythe test was used for one-way analysis and post hoc difference testing (Tomarken \& Serlin, 1986). For all analyses, the SPSS Version 24 was used.

In both samples, scale items had missing data (5.7\% and $7.3 \%)$. They were treated as

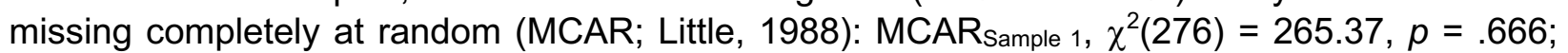
MCAR $_{\text {sample } 2,} \chi^{2}(218)=241.59, p=.131$. All missing values were estimated by means of the twostep iterative expectation-maximization algorithm. Though this method appears to be at risk to underestimate the standard errors of imputed data, in view of the small amount of missing data, its use was considered justified (Graham, 2012).

\section{Results}

Descriptive information is provided in Table 1. Standardized $z$ scores of skewness and kurtosis did not demonstrate significant deviation from the normal distribution assumption.

Table 1. Descriptive Statistics and Reliabilities of Measures

\begin{tabular}{|c|c|c|c|c|c|c|c|}
\hline Variable & Range & $\%$ & $M$ & $S D$ & $\mathbf{z S}$ & $\mathbf{z K}$ & $\alpha$ \\
\hline \multicolumn{8}{|l|}{ Age } \\
\hline Sample 1 & $21-53$ & NA & 25.65 & 5.05 & & & \\
\hline Sample 2 & $20-62$ & NA & 25.45 & 4.86 & & & \\
\hline \multicolumn{8}{|c|}{ Prior statistics experiences (exam passed) } \\
\hline Sample 1 & $1-2$ & 66.4 & & & & & \\
\hline Sample 2 & $1-2$ & 57.5 & & & & & \\
\hline \multicolumn{8}{|c|}{ Academic self-concept in mathematics } \\
\hline Sample 1 & $10-54$ & NA & 29.81 & 9.81 & 1.37 & $-2.04^{*}$ & .93 \\
\hline Sample 2 & $12-53$ & NA & 31.01 & 11.43 & -0.33 & -1.84 & .94 \\
\hline \multicolumn{8}{|c|}{ Negative utility value of statistics } \\
\hline Sample 1 & $5-18$ & NA & 11.06 & 2.89 & 0.41 & -1.18 & .72 \\
\hline Sample 2 & $8-28$ & NA & 16.18 & 3.95 & 0.55 & -0.10 & .75 \\
\hline \multicolumn{8}{|c|}{ Statistics anxiety } \\
\hline Sample 1 & $17-56$ & NA & 37.92 & 8.97 & 0.41 & -1.18 & .92 \\
\hline Sample 2 & $17-63$ & NA & 40.62 & 10.79 & -0.03 & -1.66 & .94 \\
\hline \multicolumn{8}{|c|}{$\begin{array}{l}\text { Note. NA = not applicable; } z S=z \text {-standardized skewness; } z \mathrm{~K}=z \text {-standardizec } \\
\text { kurtosis. } \\
{ }^{*} p<.05 .\end{array}$} \\
\hline
\end{tabular}


Only the mathematics self-concept in Sample 1 showed a significant negative kurtosis that indicated a platykurtic distribution. Students from both samples did not significantly differ in statistics anxiety, $t(198)=-1.885, p>.05$, and mathematics self-concept, $t(198)=1.708, p>.05$. Therefore, both samples appeared to be largely comparable. Mathematics self-concept and negative utility value are treated as independent factor measures, because they are correlated (only to a lesser extent) in Sample $1(r=-.27, p<.05)$ and Sample $2(r=-.19, p>.05)$.

Three-way analyses of variance revealed in Sample 1 significant main effects of negative utility value and mathematics self-concept on statistics anxiety. Likewise, there was a significant main effect of prior statistics experience (see Table 2). However, across both levels of statistics experiences, students with high negative utility value reported a considerably higher statistics anxiety than students with a low level of negative utility value. Students displaying both strong negative utility value and a low mathematics self-concept experienced higher statistics anxiety (see Figure 2). No interaction effect was statistically significant.

Table 2. Predicting Differences in Statistics Anxiety: Analysis of Variance Results From Both Samples

\begin{tabular}{lrrrr}
\hline Factor variable & $\boldsymbol{d} \boldsymbol{f}$ & $\boldsymbol{F}$ & $\boldsymbol{p}$ & Partial $\boldsymbol{\eta}^{\mathbf{2}}$ \\
\hline Sample 1 & & & & \\
$\quad$ Prior statistics exam (PSE) & 1,112 & 5.581 & .020 & .050 \\
Mathematics self-concept (MSC) & 1,112 & 6.731 & .011 & .060 \\
Negative utility value (NUV) & 1,112 & 21.529 & .000 & .170 \\
PSE $\times$ MSC & 1,112 & 0.816 & .368 & .008 \\
PSE $\times$ NUV & 1,112 & 0.680 & .411 & .006 \\
MSC $\times$ NUV & 1,112 & 0.108 & .744 & .001 \\
\hline PSE $\times$ MSC $\times$ NUV & 1,112 & 0.035 & .852 & .000 \\
Sample 2 & & & & \\
PSE & 1,86 & 1.792 & .184 & .022 \\
MSC & 1,86 & 7.127 & .009 & .083 \\
NUV & 1,86 & 1.610 & .208 & .020 \\
\hline PSE $\times$ MSC & 1,86 & 0.861 & .356 & .011 \\
PSE $\times$ NUV & 1,86 & 1.497 & .225 & .019 \\
MSC $\times$ NUV & 1,86 & 9.471 & .003 & .107 \\
PSE $\times$ MSC $\times$ NUV & 1,86 & 1.260 & .265 & .016 \\
\hline
\end{tabular}

Furthermore, the main effect of students' prior statistics experiences especially depended on differences in the high self-concept group. Only in this group, students with a strong negative utility value reported a significantly lower level of statistics anxiety after they had already passed a statistics exam. Their counterparts who had not yet passed a statistics exam displayed a higher level of statistics anxiety (see Figure 1). Using the Brown-Forsythe procedure, this difference was statistically significant, $F(1,16)=4.369, p<.05$. All other differences between students with and without an exam were not statistically significant. 

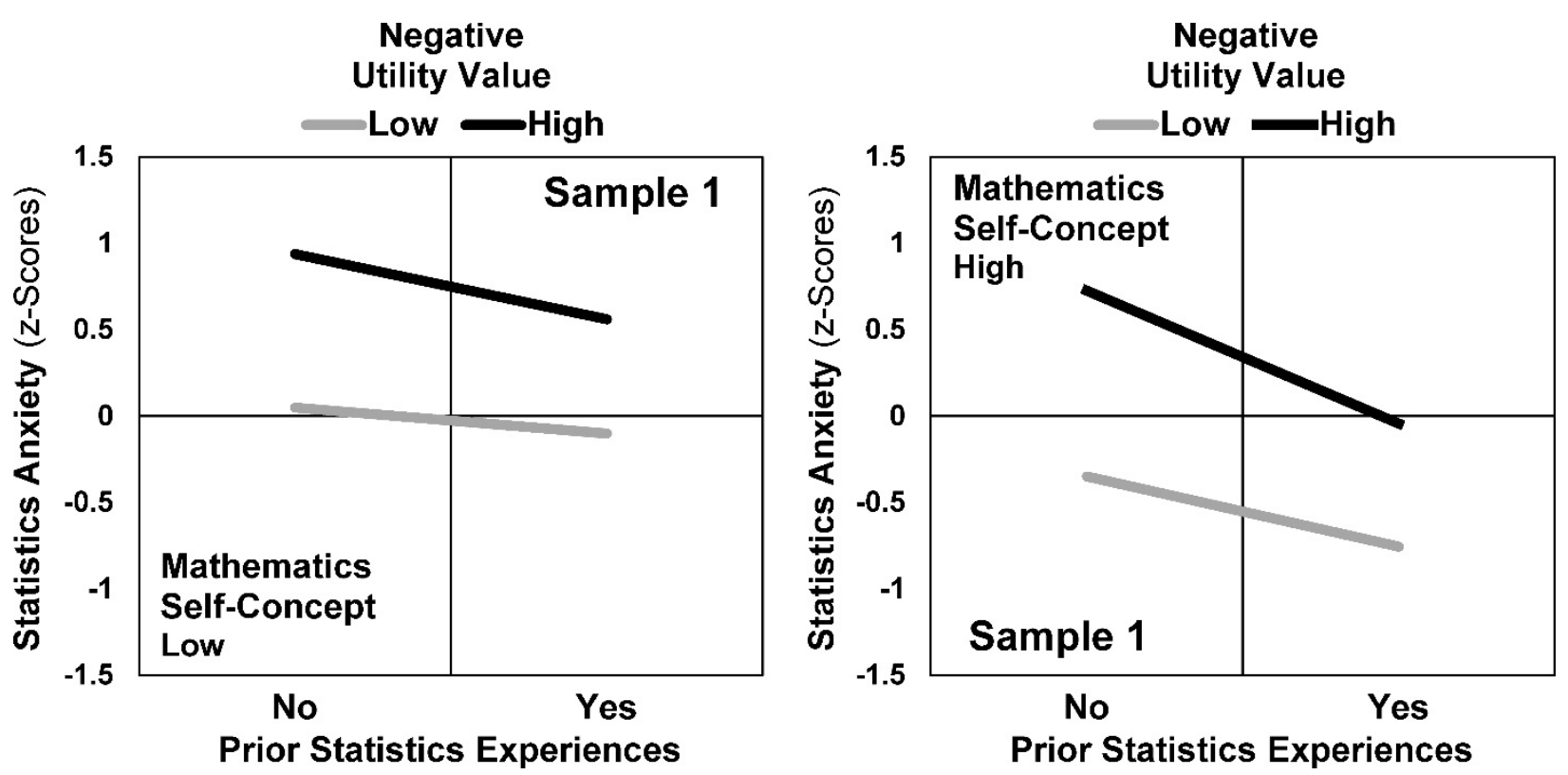

Figure 1. Statistics anxiety in Sample 1 depending on prior statistics experiences, mathematics selfconcept, and negative utility value.

In Sample 2, mean statistics anxiety scores were significantly explained by an ordinal interaction effect of the mathematics self-concept and the negative utility variable (see Table 2). Students with a low mathematics self-concept tendentially valued statistics as less useful and experienced statistics anxiety to a larger extent. Notably, this interaction effect mainly manifested in the subgroup of students who reported both a low mathematics self-concept and not yet having passed a statistics exam. Only in this particular subgroup did a high negative utility value substantially predict a higher level of statistics anxiety (see Figure 2).
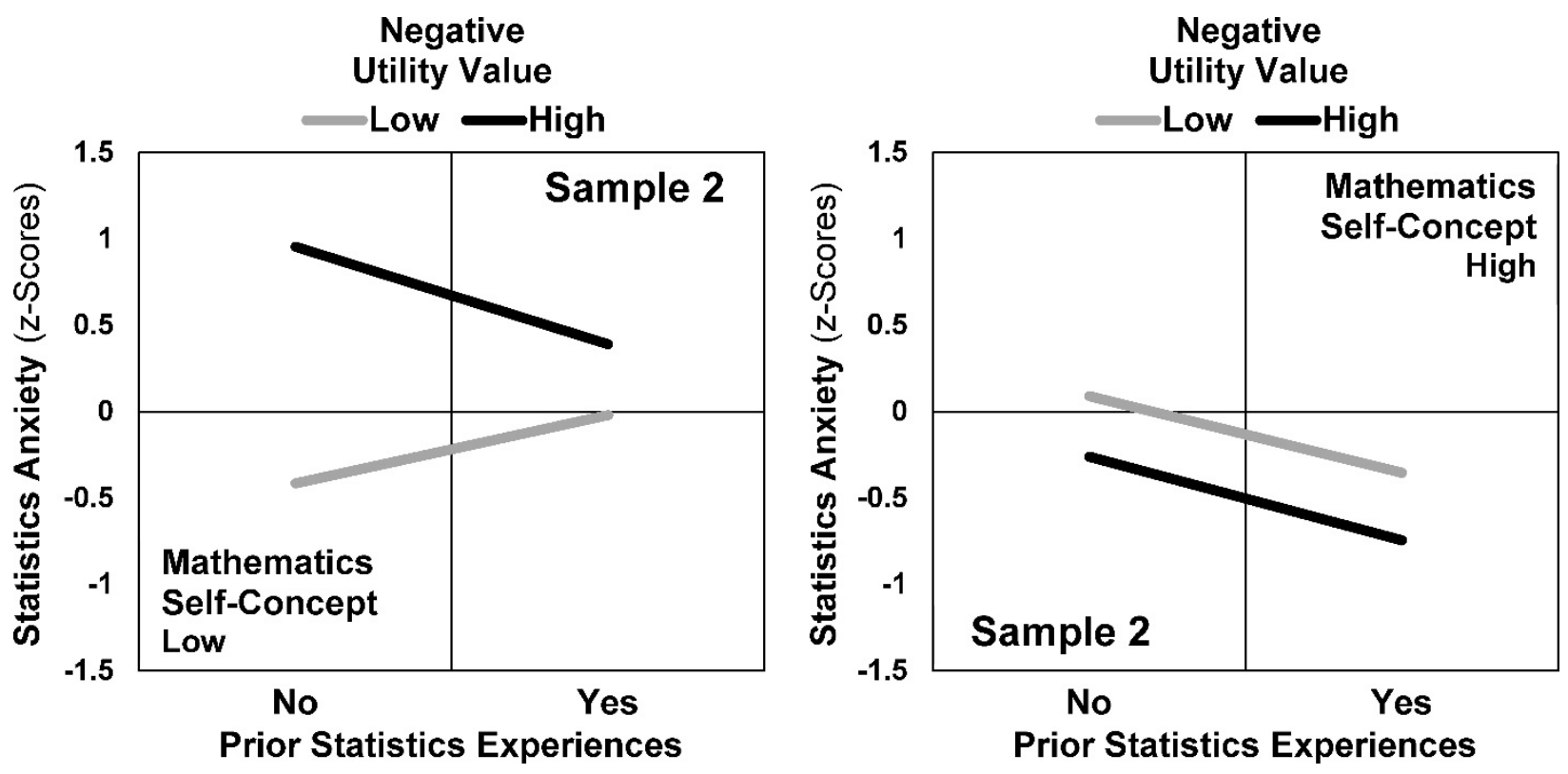

Figure 2. Statistics anxiety in Sample 2 depending on prior statistics experiences, mathematics selfconcept, and negative utility value. 
Using the Brown-Forsythe procedure, this difference was statistically significant, $F(1,9)=$ $11.948, p<.01$. In the same subgroup with a prior statistics exam, this difference did not reach statistical significance, $F(1,21)=1.330, p>.05$. Accordingly, only those students having developed low competence beliefs and who had not yet experienced an exam reported the highest level of negative utility value, which, in turn, was most strongly associated with a heightened level of statistics anxiety. However, the prior experience variable did not independently contribute to explaining students' anxiety level.

\section{Discussion}

Conceptually based on a cognitive-motivational perspective on construct relations, the present study aimed to analyze the role of prior statistics experiences to predict education science students' statistics anxiety in two independent samples. In particular, the present study primarily focused on the explanatory role of motivation variables to clarify the role of prior statistics experiences.

Confirming relevant research findings (Birenbaum \& Eylath, 1994; Chew \& Dillon, 2012, 2014a; Schutz et al., 1998; Townsend et al., 1998), the results from both samples demonstrated that prior statistics experiences predicted statistics anxiety only to a minor extent. Rather, in both samples, students' statistics anxiety appeared to be most strongly predicted by their mathematics self-concept and negative utility value. However, effect patterns evidently differed between both samples.

In Sample 1, students reporting a high negative utility value consistently displayed the highest level of statistics anxiety. Only in the high self-concept subgroup, students without statistics experiences and a high negative utility value showed a stronger level of statistics anxiety. Hence, the significant main effect of the prior experiences and self-concept variable appeared to be traced to this particular association.

In Sample 2, students reporting a low mathematics self-concept displayed a higher negative utility value, which, in turn, was associated with a higher level of statistics anxietywhether or not they had successfully passed a statistics exam. Thus, only the combination of a low mathematics self-concept and a high negative utility value explained students' heightened statistics anxiety.

Accordingly, Hypotheses 1 and 2 were substantially supported in Sample 1 and partially supported in Sample 2. Because relevant interaction effects of the prior statistics experiences with the mathematics self-concept or negative utility value variable did not occur, Hypotheses 3 and 4 were rejected. Across both samples, the direct impact of students' mathematics selfconcept on their statistics anxiety was comparable, whereas the role of their negative utility value fluctuated. Methodologically, it cannot be ruled out that the use of different scale versions to measure students' negative utility value, as well as the small size of Sample 2 and resulting limitations in the statistical power of between- and within-group comparisons (VanVoorhis \& Morgan, 2007), may have contributed to these differences in effect patterns.

Apart from this, though producing varying effect patterns in detail, the findings from both samples led to similar effects indicating the crucial role of self-belief variables. Altogether, mean differences in students' statistics anxiety substantially depended on their domain-specific competence and value beliefs. In comparison, the role of students' prior statistics experiences from their undergraduate program must considered marginal. Most remarkably, students' individually existing level of statistics anxiety did not substantially decrease even when they had successfully passed a statistics exam. In line with similar results found elsewhere (Chamberlain et al., 2014; Galli et al., 2008), this finding once more indicates the relevance of students' selfbeliefs in predicting their statistics anxiety.

According to relevant findings in the field (Chiesi \& Primi, 2010; González et al., 2016; Papousek et al., 2012), further research efforts to analyze the development of students' statistics 
anxiety should focus on motivational orientation, namely, domain-specific competence and value beliefs. In that regard, the present study's findings extend and differentiate current knowledge about the role prior statistics experiences.

\section{Educational Implications}

Completely in line with the expectancy-value and control perspective of academic selfbeliefs (Wigfield \& Eccles, 2000; Hood et al., 2012; Pekrun et al., 2007), in both samples, students' self-concept and utility value substantially explained their individually existing level of statistics anxiety across all experience levels. Hence, this finding indicates students' prior statistics experiences not being an effective predictor. To put it another way, even previously experienced success in learning statistics did not lessen students' negative valuing of statistical competencies. Because a strong negative utility value, in turn, provokes a heightened level of anxiety, it must be considered to bias students' statistical learning and course outcomes in a most unfavorable way (Markle, 2017; Papanastasiou \& Zembylas, 2008). Therefore, this particular finding stresses the need for appropriate instructional conceptualizations and learning formats (Cybinski \& Selvanathan, 2005; Schober, Wagner, Reimann, Atria, \& Spiel, 2006) which should pay more attention to students' self-beliefs and, most urgently, their task values (Chiesi \& Primi, 2018). Otherwise, method courses are at risk to unwantedly impede the learning of statistics and to produce insufficient learning outcomes.

Instead, beyond the teaching of statistical knowledge and procedures (Garfield \& Ben-Zvi, 2007), method courses should more strongly emphasize the meaning of statistical competencies for students' professional development in relevant vocational settings (Slootmaeckers, Adriaensen, \& Kerremans, 2013; Wiberg, 2009). In particular, they should offer detailed indications and practical training projects to make comprehensible how empirical analyses and quantitative procedures can help to describe, explain, and modify developmental, academic and vocational, or organizational phenomena in a certain educational setting students will probably encounter-such as concerning their professional decision of appropriate treatments, their perspectives to optimize social structures, and their supportive strategies to enhance individual or collective developments. In that regard, such teaching efforts should not only concern relevant method courses, they should also strive for a close linkage between methodological and substantive contents in other courses of a program (Adriaensen, Coremans, \& Kerremans, 2014; M. Williams et al., 2016).

\section{Limitations and Perspectives}

With all that, the present study undeniably suffers from some conceptual and empirical limitations. First of all, the composition and size of both student samples do not allow for generalizing empirical findings. Instead, the findings reported here might claim a sort of local validity - all the more because their data basis referred to a certain university setting. Therefore, their external validity must be considered weak, and further analyses should attempt to replicate the findings in larger student samples in other educational science contexts. There would also be benefit to assessing prior experiences in a more differentiated way (e.g., by concurrently analyzing various indicators such as course grades, exams passed, and students' subjective appraisals of outcomes).

Furthermore, all analyses were based on cross-sectional data. Following the expectancyvalue framework of motivational beliefs, the relations among constructs as hypothesized in the present study reflect a certain conceptual perspective which must be considered being dynamic over time. Principally, the relations among constructs should be reciprocal in nature (Ahmed et al., 2012; Pekrun, Lichtenfeld, Marsh, Murayama, \& Goetz, 2017). Though students' self-concept and utility value undoubtedly represent important predictor variables to explain the individually 
existing level of statistics anxiety, they might also operate as consequences of statistics anxiety in the long term. Therefore, prospective analyses of longitudinal data should allow for more differentiated insights into the interplay between constructs. In this respect, it would be worthwhile to investigate the role of negative utility beliefs as an individually emerged coping strategy. As relevant studies could demonstrate elsewhere, the devaluing of threatening events or competence areas might indicate students' approach to protecting their current self-system against actually experienced or mentally anticipated failure outcomes (Stephan, Caudroit, Boiché, \& Sarrazin, 2012) —and, thus, constitute a certain form of motivational disengagement (Régner \& Losse, 2006; Schmader, Major, \& Gramzow, 2001).

\section{References}

Adriaensen, J., Coremans, E., \& Kerremans, B. (2014). Overcoming statistics anxiety: Towards the incorporation of quantitative methods in non-methodological courses. European Political Science, 13, 251-265. http://dx.doi.org/10.1057/eps.2014.8

Ahmed, W., Minnaert, A., Kuyper, H., \& van der Werf, G. (2012). Reciprocal relationships between math self-concept and math anxiety. Learning and Individual Differences, 22, 385-389. http://dx.doi.org/10.1016/j.lindif.2011.12.004

Baloğlu, M. (2002). Psychometric properties of the Statistics Anxiety Rating Scale. Psychological Reports, 90, 315-325. http://dx.doi.org/10.2466/pr0.2002.90.1.315

Bandalos, D. L., Yates, K., \& Thorndike-Christ, T. (1995). Effects of math self-concept, perceived selfefficacy, and attributions for failure and success on test anxiety. Journal of Educational Psychology, 87, 611-623. http://dx.doi.org/10.1037/0022-0663.87.4.611

Benson, J. (1989). Structural components of statistical test anxiety in adults: An exploratory model. Journal of Experimental Education, 57, 247-261. http://dx.doi.org/10.1080/00220973.1989.10806509

Birenbaum, M., \& Eylath, S. (1994). Who is afraid of statistics? Correlates of statistics anxiety among students of educational sciences. Educational Research, 36, 93-98. http://dx.doi.org/10.1080/0013188940360110

Cano, F., Martin, A. J., Ginns, P., \& Berbén, A. B. G. (2018). Students' self-worth protection and approaches to learning in higher education: Predictors and consequences. Higher Education, 76, 163-181. http://dx.doi.org/10.1007/s10734-017-0215-0

Carmona, J., Martínez, R. J., \& Sánchez, M. (2005). Mathematical background and attitudes toward statistics in a sample of Spanish college students. Psychological Reports, 97, 53-62. http://dx.doi.org/10.2466/pr0.97.1.53-62

Chamberlain, J. M., Hillier, J., \& Signoretta, P. (2014). Counting better? An examination of the impact of quantitative method teaching on statistical anxiety and confidence. Active Learning in Higher Education, 16, 51-66. http://dx.doi.org/10.1177/1469787414558983

Chew, K. H., \& Dillon, D. (2012, May). Statistics anxiety fluctuates over a semester and decreases with experience. Presented at the 24th annual convention of the Association for Psychological Science, Chicago, IL.

Chew, K. H. P., \& Dillon, D. B. (2014a). Individual differences in statistics anxiety among students in Singapore. In P. Mandal (Ed.), Proceedings of the international conference on managing the Asian century (pp. 293-302).Singapore: Springer.

Chew, K. H. P., \& Dillon, D. (2014b). Statistics anxiety update: Refining the construct and recommendations 
for a new research agenda. Perspectives on Psychological Science, 9, 196-208. http://dx.doi.org/10.1177/1745691613518077

Chiesi, F., \& Primi, C. (2010). Cognitive and non-cognitive factors related to students' statistics achievement. Statistics Education Research Journal, 9, 6-26.

Chiesi, F., \& Primi, C. (2018). What happens when attitudes toward statistics change (increase vs. decrease) during the course? In M. A. Sorto, A. White, \& L. Guyot (Eds.), Looking back, looking forward: Proceedings of the tenth international conference on teaching statistics (ICOTS10; pp. 16). Voorburg, The Netherlands: International Statistical Institute.

Cruise, R. J., Cash, R. W., \& Bolton, D. L. (1985). Development and validation of an instrument to measure statistical anxiety. In American Statistical Association 1985 proceedings of the Section on Statistical Education (pp. 92-97). Washington, DC: American Statistical Association.

Cybinski, P., \& Selvanathan, S. (2005). Learning experience and learning effectiveness in undergraduate statistics: Modeling performance in traditional and flexible learning environments. Decision Sciences Journal of Innovative Education, 3, 251-271. http://dx.doi.org/10.1111/j.15404609.2005.00069.x

Dempster, M., \& McCorry, N. K. (2009). The role of previous experience and attitudes toward statistics in statistics outcomes among undergraduate psychology students. Journal of Statistics Education, 17, 1-6. http://dx.doi.org/10.1080/10691898.2009.11889515

Emmioğlu, E., \& Capa-Aydin, Y. (2012). Attitudes and achievement in statistics: A meta-analysis study. Statistics Education Research Journal, 11, 95-102.

Faber, G. (2012). Elementary school children's spelling-specific self-beliefs: Longitudinal analyses of their relations to academic achievement, school attitudes, and self-esteem. New York, NY: Nova Science.

Faber, G., Drexler, H., Stappert, A., \& Eichhorn, J. (2018). Education science students' statistics anxiety: Developing and analyzing a scale for measuring their worry, avoidance, and emotionality cognitions. International Journal of Educational Psychology, 7, 248-285. http://dx.doi.org/10.17583/ijep.2018.3340

Field, A. (2013). Discovering statistics using SPSS (4th ed.). Los Angeles, CA: Sage.

Finney, S. J., \& Schraw, G. (2003). Self-efficacy beliefs in college statistics courses. Contemporary Educational Psychology, 28, 161-186. http://dx.doi.org/10.1016/S0361-476X(02)00015-2

Galli, S., Ciancaleoni, M., Chiesi, F., \& Primi, C. (2008, July). Who failed the introductory statistics examination? A study on a sample of psychology students. Paper presented at the 11th International Congress on Mathematical Education, Monterrey, Mexico.

Garfield, J., \& Ben-Zvi, D. (2007). How students learn statistics revisited: A current review of research on teaching and learning statistics. International Statistical Review, 75, 372-396. http://dx.doi.org/10.1111/j.1751-5823.2007.00029.x

Goetz, T., Pekrun, R., Hall, N., \& Haag, L. (2006). Academic emotions from a social-cognitive perspective: Antecedents and domain-specificity of students' affect in the context of Latin instruction. British Journal of Educational Psychology, 76, 289-308. http://dx.doi.org/10.1348/000709905X42860 
González, A., Rodrígez, Y., Faílde, J. M., \& Carrera, M. V. (2016). Anxiety in the statistics class: Structural relations with self-concept, intrinsic value, and engagement in two samples of undergraduates. Learning and Individual Differences, 45, 214-221. http://dx.doi.org/10.1016/j.lindif.2015.12.019

Graham, J. W. (2012). Missing data: Analysis and design. New York, NY: Springer.

Hannigan, A., Hegarty, A. C., \& McGrath, D. (2014). Attitudes towards statistics of graduate entry medical students: The role of prior learning experiences. BMC Medical Education, 14, 70. http://dx.doi.org/10.1186/1472-6920-14-70

Hodapp, V., \& Benson, J. (1997). The multidimensionality of test anxiety: A test of different models. Anxiety, Stress, and Coping, 10, 219-244. http://dx.doi.org/10.1080/10615809708249302

Hood, M., Creed, P. A., \& Neumann, D. L. (2012). Using the expectancy value model of motivation to understand the relationship between student attitudes and achievement in statistics. Statistics Education Research Journal, 11, 72-85.

Kesici, S., Baloğlu, M., \& Deniz, M. E. (2011). Self-regulated learning strategies in relation with statistics anxiety. Learning and Individual Differences, 21, 472-477. http://dx.doi.org/10.1016/j.lindif.2011.02.006

Little, R. J. A. (1988). A test of missing completely at random for multivariate data with missing values. Journal of the American Statistical Association, 83, 1198-1202. http://dx.doi.org/10.1080/01621459.1988.10478722

Macher, D., Paechter, M., Papousek, I., \& Ruggeri, K. (2012). Statistics anxiety, trait anxiety, learning behavior, and academic performance. European Journal of Psychology of Education, 27, 483-498. http://dx.doi.org/10.1007/s10212-011-0090-5

Macher, D., Paechter, M., Papousek, I., Ruggeri, K., Freudenthaler, H. H., \& Arendasy, M. (2013). Statistics anxiety, state anxiety during an examination, and academic achievement. British Journal of Educational Psychology, 83, 535-549. http://dx.doi.org/10.1111/j.2044-8279.2012.02081.x

Markle, G. (2017). Factors influencing achievement in undergraduate social science research methods courses: A mixed methods analysis. Teaching Sociology, 45, 105-115. http://dx.doi.org/10.1177/0092055X16676302

Mji, A., \& Onwuegbuzie, A. J. (2004). Evidence of score reliability and validity of the Statistical Anxiety Rating Scale among technikon students in South Africa. Measurement and Evaluation in Counseling and Development, 36, 238-251. http://dx.doi.org/10.1080/07481756.2004.11909745

Möller, J., Streblow, L., Pohlmann, B., \& Köller, O. (2006). An extension to the internal/external frame of reference model to two verbal and numerical domains. European Journal of Psychology of Education, 21, 467-487. http://dx.doi.org/10.1007/BF03173515

Murtonen, M., \& Lehtinen, E. (2003). Difficulties experienced by education and sociology students in quantitative methods courses. Studies in Higher Education, 28, 171-185. http://dx.doi.org/10.1080/0307507032000058064

Murtonen, M., Olkinuora, E., Tynjälä, P., \& Lehtinen, E. (2008). "Do I need research skills in working life?" University students' motivation and difficulties in quantitative method courses. Higher Education, 56, 599-612. http://dx.doi.org/10.1007/s10734-008-9113-9

Nasser, F. M. (2004). Structural model of the effects of cognitive and affective factors on the achievement of Arabic-speaking pre-service teachers in introductory statistics. Journal of Statistics Education, 12, 1-18. http://dx.doi.org/10.1080/10691898.2004.11910717

Onwuegbuzie, A. J. (2000). Statistics anxiety and the role of self-perceptions. Journal of Educational 
Research, 93, 323-330. http://dx.doi.org/10.1080/00220670009598724

Onwuegbuzie, A. J. (2003). Modeling statistics achievement among graduate students. Educational and Psychological Measurement, 63, 1020-1038. http://dx.doi.org/10.1177/0013164402250989

Onwuegbuzie, A. J., \& Wilson, V. A. (2003). Statistics anxiety: Nature, etiology, antecedents, effects and treatments-a comprehensive review of the literature. Teaching in Higher Education, 8, 195-209. http://dx.doi.org/10.1080/1356251032000052447

Paechter, M., Macher, D., Martskvishvili, K., Wimmer, S., \& Papousek, I. (2017). Mathematics anxiety and statistics anxiety: Shared but also unshared contributions and antagonistic contributions to $\begin{array}{llllll}\text { performance in statistics. Frontiers in Psychology, } & 1196 .\end{array}$ http://dx.doi.org/10.3389/fpsyg.2017.01196

Papanastasiou, E. C., \& Zembylas, M. (2008). Anxiety in undergraduate research methods courses: Its nature and implications. International Journal of Research and Method in Education, 31, 155-167. http://dx.doi.org/10.1080/17437270802124616

Papousek, I., Ruggeri, K., Macher, D., Paechter, M., Heene, M., Weiss, E. M., . . Freudenthaler, H. (2012). Psychometric evaluation and experimental validation of the Statistics Anxiety Rating Scale. Journal of Personality Assessment, 94, 82-91. http://dx.doi.org/10.1080/00223891.2011.627959

Pekrun, R. (1988). Anxiety and motivation in achievement settings: Towards a system-theoretical approach. International Journal of Educational Research, 12, 307-323.

Pekrun, R., Frenzel, A., Goetz, T., \& Perry, R. P. (2007). The control-value theory of achievement emotions: An integrative approach to emotions in education. In P. A. Schulz, \& R. Pekrun (Eds.), Emotions in education (pp. 13-36). San Diego, CA: Academic Press.

Pekrun, R., Lichtenfeld, S., Marsh, H. W., Murayama, K., \& Goetz, T. (2017). Achievement emotions and academic performance: Longitudinal models of reciprocal effects. Child Development, 88, 16541670. http://dx.doi.org/10.1111/cdev.12704

Pituch, K. A., \& Stevens, J. P. (2016). Applied multivariate statistics for the social sciences: Analyses with SAS and IBM's SPSS (6th ed.). New York, NY: Routledge.

Podsakoff, P. M., MacKenzie, S. B., Lee, J.-Y., \& Podsakoff, N. P. (2003). Common method biases in behavioral research: A critical review of the literature and recommended remedies. Journal of Applied Psychology, 88, 879-903. http://dx.doi.org/10.1037/0021-9010.88.5.879

Ralston, K., Maclnnes, J., Crow, G., \& Gayle, V. (2016). We need to talk about statistical anxiety: A review of the evidence around statistical anxiety in the context of quantitative methods pedagogy (Working paper 4/16). Edinburgh, Scotland: University of Edinburgh, National Centre for Research Methods.

Régner, I., \& Loose, F. (2006). Relationship of sociocultural factors and academic self-esteem to school grades and school disengagement in North African French adolescents. British Journal of Social Psychology, 45, 777-797. http://dx.doi.org/10.1348/014466605X83610

Rost, D. H., \& Schermer, F. J. (1989). The various facets of test anxiety: A subcomponent model of test anxiety measurement. In R. Schwarzer, H. M. van der Ploeg, \& C. D. Spielberger (Eds.), Advances in test anxiety research (Volume 6; pp. 36-52) Lisse, The Netherlands: Swets and Zeitlinger. 
Rost, D. H., Sparfeldt, J. R., \& Schilling, S. R. (2007). DISK-Gitter mit SKSLF-8: Differentielles Selbstkonzept-Gitter mit Skala zur Erfassung des Selbstkonzepts schulischer Leistungen und Fähigkeiten [The Self-Concept Grid: A questionnaire for measuring subject-specific facets of academic self-concept]. Göttingen, Germany: Hogrefe.

Sarason, I. G. (1984). Stress, anxiety, and cognitive interference: Reactions to tests. Journal of Personality and Social Psychology, 46, 929-938. http://dx.doi.org/10.1037/0022-3514.46.4.929

Schmader, T., Major, B., \& Gramzow, R. H. (2001). Coping with ethnic stereotypes in the academic domain: Perceived injustice and psychological disengagement. Journal of Social Issues, 57, 93-111. http://dx.doi.org/10.1111/0022-4537.00203

Schober, B., Wagner, P., Reimann, R., Atria, M., \& Spiel, C. (2006). Teaching research methods in an Internet-based blended-learning setting. Methodology, 2, 73-82. http://dx.doi.org/10.1027/1614$\underline{2241.2 .2 .73}$

Schönwetter, D. J., Clifton, R. A., \& Perry, R. P. (2002). Content familiarity: Differential impact of effective teaching on student achievement outcomes. Research in Higher Education, 43, 625-655. http://dx.doi.org/10.1023/A:1020999014875

Schutz, P. A., Drogosz, L. M., White, V. E., \& DiStefano, C. (1998). Prior knowledge, attitude, and strategy use in an introduction to statistics course. Learning and Individual Differences, 10, 291-308. http://dx.doi.org/10.1016/S1041-6080(99)80124-1

Schwarzer, R. (1996). Thought control of action: Interfering self-doubts. In I. G. Sarason, G. R. Pierce, \& B. R. Sarason (Eds.), Cognitive interference: Theory, methods and findings (pp. 99-115). Mahwah, NJ: Erlbaum.

Sesé, A., Jiménez, R., Montaño, J.-J., \& Palmer, A. (2015). Can attitudes towards statistics and statistics anxiety explain students' performance? Revista de Psicodidáctica, 20, 285-304. http://dx.doi.org/10.1387/RevPsicodidact.13080

Slootmaeckers, K. (2012, July). Too afraid to learn?! Attitudes towards statistics as a barrier to learning statistics and to acquiring quantitative skills. Paper presented at the 4th International Conference on Education and New Learning Technologies, Barcelona, Spain.

Slootmaeckers, K., Adriaensen, J., \& Kerremans, B. (2013, February). Taking research methods out of isolation: Teachers' experiences with curriculum-wide integration of research methods in substantive courses. Paper presented at the APSA Teaching and Learning Conference, Long Beach, CA.

Spada, M. M., \& Moneta, G. B. (2012). A metacognitive-motivational model of surface approach to studying. Educational Psychology, 32, 45-62. http://dx.doi.org/10.1080/01443410.2011.625610

Stephan, Y., Caudroit, J., Boiché, J., \& Sarrazin, P. (2011). Predictors of situational disengagement in the academic setting: The contribution of grades, perceived competence, and academic motivation. British Journal of Educational Psychology, 81, 441-455. http://dx.doi.org/10.1348/000709910X522285

Stiensmeier-Pelster, J., \& Otterpohl, N. (2018). Motivation at school and university. In J. Heckhausen \& H. Heckhausen (Eds.), Motivation and action (3rd ed., pp. 783-817). Cham, Switzerland: Springer.

Sutarso, T. (1992, November). Some variables in relation to students' anxiety in learning statistics. Paper presented at the Annual Meeting of the Mid-South Educational Research Association, Knoxville, TN. 
Tomarken, A. J., \& Serlin, R. C. (1986). Comparison of ANOVA alternatives under variance heterogeneity and specific noncentrality structures. Psychological Bulletin, 99, 90-99. http://dx.doi.org/10.1037/0033-2909.99.1.90

Townsend, M. A. R., Moore, D. W., Tuck, B. F., \& Wilton, K. M. (1998). Self-concept and anxiety in university students studying social science statistics within a co-operative learning structure. Educational Psychology, 18, 41-54. http://dx.doi.org/10.1080/0144341980180103

Tremblay, P. F., Gardner, R. C., \& Heipel, G. (2000). A model of the relationships among measures of affect, aptitude, and performance in introductory statistics. Canadian Journal of Behavioural Science, 32, 40-48. http://dx.doi.org/10.1037/h0087099

VanVoorhis, C. R. W., \& Morgan, B. L. (2007). Understanding power and rules of thumb for determining sample size. Tutorials in Quantitative Methods for Psychology, 3, 43-50. http://dx.doi.org/10.20982/tqmp.03.2.p043

Virtanen, P., Nevgi, A., \& Niemi, H. (2013). Self-regulation in higher education: Students' motivational, regulational, and learning strategies, and their relationship to study success. Studies for the Learning Society, 3, 20-36. http://dx.doi.org/10.2478/sls-2013-0004

von der Embse, N., Jester, D., Roy, D., \& Post, J. (2018). Test anxiety effects, predictors, and correlates: A 30-year meta-analytic review. Journal of Affective Disorders, 227, 483-493. http://dx.doi.org/10.1016/j.jad.2017.11.048

Waples, J. A. (2016). Building emotional support with students in statistics courses. Scholarship of Teaching and Learning in Psychology, 2, 285-293. http://dx.doi.org/10.1037/stl0000071

Warr, P., \& Downing, J. (2000). Learning strategies, learning anxiety and knowledge acquisition. British Journal of Educational Psychology, 91, 311-333. http://dx.doi.org/10.1348/000712600161853

Wiberg, M. (2009). Teaching statistics in integration with psychology. Journal of Statistics Education, 17, 1-16. http://dx.doi.org/10.1080/10691898.2009.11889509

Wigfield, A., \& Eccles, J. S. (2000). Expectancy-value theory of achievement motivation. Contemporary Educational Psychology, 25, 68-81. http://dx.doi.org/10.1006/ceps.1999.1015

Wigfield, A., Hoa, L. W., \& Klauda, S. L. (2009). The role of achievement values in the regulation of achievement behaviors. In D. H. Schunk, \& B. J. Zimmerman (Eds.), Motivation and self-regulated learning: Theory, research, and applications (pp. 169-195). New York, NY: Routledge.

Williams, A. (2014). An exploration of preference for numerical information in relation to math self-concept and statistics anxiety in a graduate statistics course. Journal of Statistics Education, 22, 1-16. http://dx.doi.org/10.1080/10691898.2014.11889693

Williams, M., Sloan, L., Cheung, S. Y., Sutton, C., Stevens, S., \& Runham, L. (2016). Can't count or won't count? Embedding quantitative methods in substantive sociology curricula: A quasi-experiment. Sociology, 50, 435-452. http://dx.doi.org/10.1177/0038038515587652

Zeidner, M. (1991). Statistics and mathematics anxiety in social science students: Some interesting parallels. British Journal of Educational Psychology, 61, 319-328. http://dx.doi.org/10.1111/j.20448279.1991.tb00989.x

Zeidner, M. (1998). Test anxiety: The state of the art. New York, NY: Plenum. 